\title{
Síndrome de Caim: Psicologia Escolar, Psicopedagogia e o "fracasso escolar" como mercado de trabalho
}

\author{
Margareth R. B. Lima Jucá \\ Universidade Federal do Rio Grande de Norte
}

A despeito da inegável ampliação das oportunidades educaci onais no nível do ensino básico experimentada nos últimos anos, qualquer diagnóstico da situação da educação no nosso país apontará, como duas de suas características mais significaticas, altas taxas de analfabetismo e baixos índices de escolaridade.

Uma vez que a grande maioria da população brasileira passa, mesmo que precariamente, pelos bancos escolares, as características antes apontadas articulam-se com as trajetórias escolares "típicas": repetência e evasão como conseqüências do "fracasso escolar".

Não é nosso objetivo discutir, especificamente, a questão do fracasso escolar; apenas colocar em evidência que tal dificuldade é, sobretudo, da escola e não do aluno.

A questão que nos importa aqui é que tal fracasso produzido pela escola possibilita o surgimento de algumas práticas e conhecimentos especializados na questão. No Brasil, a Psicologia e, em particular, a Psicologia Escolar, é um exemplo de profissão que se dedica a essa questão já há algum tempo. Mais recentemente, no entanto, tem estado em evidência a Psicopedagogia como mais um conhecimento/ocupação interessado na problemática do fracasso escolar. Muito embora esteja longe de se constituir em uma novidade de fato - basta lembrar 
que ela faz parte das atribuições regulamentadas do psicólogo - ela tem se apresentado como área nova no Brasil e reivindicado, através da Associação Brasileira de Psicopedagogia (ABPp), a possibilidade de vir a tornar-se uma profissão legalmente reconhecida.

Essa temática vem a público de forma explosiva em virtude da postura assumida pelo Conselho Federal de Psicologia (CFP), apresentando um conjunto de argumentos contrários ao reconhecimento da profissão de psicopedagogo.

Por que razões o CFP assume essa posição? Uma análise da questão torna-se necessária se quisermos compreender os posicionamentos teóricos da Psicologia e da Psicopedagogia, a relação entre eles e os possíveis interesses envolvidos em todo esse processo.

A Psicologia, a partir de seu Conselho Federal, afirma, em artigo de divulgação nacional (CFP, 1999), que a Psicopedagogia, em particular, a parcela representada pela ABPp, não pode ser profissão devido a alguns aspectos que prejudicariam ou impediriam esse processo. Os mais importantes seriam: características de formação, atuação, base teórica, técnicas utilizadas e interesses pelo mercado. No que diz respeito à formação da maioria dos psicopedagogos brasileiros, o CFP afirma que "especialização não é profissão". Com esse aspecto ele traz à tona a complexa questão da especialização (pós-"qualquer"graduação) versus formação universitária. Qual desses seria o profissional mais capacitado? Quanto à atuação, o CFP argumenta que o psicopedagogo sustenta na análise do fracasso escolar, basicamente, uma perspectiva equivocada (individual), buscando preferencialmente no aluno as causas desses problemas. Acusa a Psicopedagogia de utilizar-se quase que exclusivamente dos conhecimentos psicológicos, inviabilizando sua autenticidade e especificidade, argumentando que uma teoria nova não pode construir-se dessa maneira. O CFP também sustenta que a Psicopedagogia utiliza-se indevidamente dos métodos e técnicas psicológicos e pedagógicos, devendo às duas áreas (Psicologia e Pedagogia) o seu instrumental de trabalho. E ainda, que ela estaria, na verdade com "interesses escusos", exclusivamente de mercado ao reivindicar sua profissionalização, aproveitando-se da precariedade da situação da escola brasileira. 
Caso consideremos algumas características da Psicopedagogia, a partir de sua literatura, podemos pensar que o Conselho Federal de Psicologia talvez esteja com a razão. A Psicopedagogia, enquanto uma área que se pretende independente, é recente no Brasil, apresentando-se, segundo Bossa (1994), como um conhecimento que, recorrendo à Psicologia e à Pedagogia, pensa seu objeto de estudo a partir de um corpo teórico próprio. Mesmo constituindo-se a partir de uma proposta interdisciplinar, sua especificidade estaria no seu objeto, que seria o problema de aprendizagem. As várias concepções que formam o corpo teórico da Psicopedagogia seriam a Lingüística, a Psicologia Social, a Psicologia Genética, a Psicanálise, dentre outras (Bossa, 1994). Quanto aos campos de atuação, a Psicopedagogia poderia ser Clínica e/ou Institucional. A atividade clínica caracterizar-se-ia pelo atendimento em consultório, do tipo terapêutico, no intuito de reconhecer e atender às alterações de aprendizagem de natureza patológica. Sua principal técnica de trabalho seria o diagnóstico psicopedagógico. Outra modalidade de atuação seria a Preventiva ou Institucional, aquela na qual a prática seria a adoção de uma postura mais "crítica" frente ao fracasso escolar, a partir de uma visão mais totalizante (Bossa, 1994).

A partir dos aspectos apresentados, podemos perceber que a Psicopedagogia parece enfatizar o problema de aprendizagem em sua literatura e atuação, isto é, o Psicopedagogo concentra-se nos aspectos individuais do processo de ensino-aprendizagem. Parece haver uma diferença, também, entre a base teórica e a prática Clínica e a Institucional. Grande parte da literatura existente sobre a Psicopedagogia e sua prática no Brasil, é sobre a clínica e o diagnóstico psicopedagógico (Jucá, 1999). Essa ênfase parece sugerir que a literatura psicopedagógica brasileira sustenta um "círculo vicioso" em que, ao mesmo tempo que alimenta uma prática clínica, é também alimentada por ela. Seus cursos de formação são de especialização em caráter lato senso, em instituições públicas e particulares, aceitando graduados das mais variadas áreas (Bossa, 1994). Habilitar para uma profissão um especialista em Psicopedagogia oriundo de graduações cuja base teórica nada têm a ver com os conhecimentos psicológicos e/ou pedagógicos expostos durante o curso, com todos os riscos que 
poderia acarretar para o exercício profissional, parece não se constituir em motivo de preocupação.

Sendo a Psicologia responsável pelo repúdio à proposta de profissionalização da Psicopedagogia, representada pelos argumentos acima, parece-nos que a conclusão mais óbvia seria a de que ela mesma está isenta de acusações semelhantes. No entanto, esta conclusão não parece sustentar-se.

O psicólogo no Brasil, apesar de ser um profissional generalista (com formação ampla para atuar em diversas áreas), tem sido apontado, desde o estudo de Mello (1975), como representante de uma "profissão de luxo" devido à sua preferência pelo trabalho em consultórios particulares, na chamada área clínica. Essa tendência acaba por definir uma postura no psicólogo que, quando não faz opção direta pela área clínica, atua noutras áreas da Psicologia reproduzindo uma visão terapêutica nas suas atividades. A área da Psicologia que lida com a educação é um excelente exemplo. O Sindicato dos Psicólogos de São Paulo e o Conselho Regional de Psicologia - 6 a . Região (1984) organizaram uma pesquisa na qual constataram que, considerando somente a atividade principal, 57,5\% atuavam na Clínica contra 11,9\% da área Escolar. Em 1988, Bastos constatou que apenas 14,7\% dos psicólogos brasileiros escolhiam a área Escolar para seu trabalho. Além disso, 50,2\% desses psicólogos a abandonavam devido à baixa remuneração e à falta de condições de trabalho migrando para a área Clínica. No Rio Grande do Norte, Yamamoto et al. (1990) descreveram a situação dos psicólogos escolares em Natal. Dentre as atividades realizadas por esses profissionais, $50 \%$ privilegiava sua atenção nos alunos, a despeito de atender a escola como um todo. Noutro estudo, Yamamoto, Spinelli e Carvalho (1996) verificaram que, dentre 11 psicólogos entrevistados, nenhum havia feito estágio na área Escolar e 9 deles realizado na área Clínica. Esses dados parecem corroborar os estudos nacionais que apontavam a "vocação" Clínica da Psicologia enquanto profissão, ao mesmo tempo em que demonstram que a Psicologia Escolar não é exceção a essa regra.

Estudos apontando outras possibilidades, no entanto, também foram publicados. Reger (1981), Andaló (1984) e Ribeiro e Guzzo (s.d.) 
discutiram essa forma de atuação do psicólogo escolar e a criticaram, vindo a apontar formas de atuação alternativas, as quais tinham em comum a crítica a uma prática terapêutica na escola. Eles apontaram que o problema que a criança tem na escola, caso venha a ser rotulado como problema de aprendizagem, requerendo um atendimento individualizante, exclui de toda possibilidade de análise a escola e seu ensino. Quando o psicólogo foca sua atenção apenas no aluno, ele não considera a responsabilidade da escola e o processo pedagógico como possível fonte das dificuldades existentes e deixa de atuar como um "agente de mudanças", para proceder como um terapeuta acrítico e preconceituoso. Maluf (1994) aponta que o psicólogo escolar tem construído uma postura crítica a respeito dessas questões e que em seus cursos de formação já constam mais disciplinas da área Escolar comprometidas com esse desafio: não mais focar exclusivamente no aluno a responsabilidade pelo fracasso escolar.

A partir da situação da Psicologia no Brasil, somos obrigados a questionar a consistência dos argumentos do CFP. Quanto à formação do psicopedagogo, concordamos com o fato de ser precária e sem identidade. Mas, falando-se em termos de Psicologia, a pequena quantidade de disciplinas em Psicologia Escolar existente nos nossos cursos brasileiros, a partir de nosso diploma generalista, capacita melhor o psicólogo para trabalhar na escola do que os conhecimentos que formaram um pedagogo com especialização em Psicopedagogia? A partir dessa conjectura, somos obrigados a admitir que torna-se, no mínimo, apressada a conclusão do CFP quanto à competência dos especialistas ao generalizar a problemática no caso da Psicopedagogia.

Quanto à atuação da Psicopedagogia, será que o CFP esqueceuse da história da Psicologia com a escola? Mesmo tendo que reconhecer que a Psicologia não pode ser tratada monoliticamente, vindo a negar seus embates internos entre posições críticas e apologéticas em relação a um "olhar" terapêutico na produção de conhecimento e atuação profissional, vimos que a Psicologia é marcada por um viés clínico, do tipo individualizante, inclusive na atuação escolar. Se é verdade que há uma luta para que a Psicologia Escolar construa uma identidade própria, a partir de um modelo mais totalizante da relação 
ensino-aprendizagem, também é que ela ainda não o conseguiu por completo. Portanto, parece estranho perceber que esse é justamente um dos argumentos mais utilizados pelo CFP, levando a pensar que o mesmo desconhece os percursos "positivos" e "negativos" da Psicologia Escolar até hoje.

Quanto ao fato da Psicopedagogia utilizar-se de conhecimentos psicológicos e pedagógicos para constituir-se, perguntamos: mas não é exatamente assim que surge uma nova ciência/profissão? A Psicologia também não contém base teórica noutras ciências como Biologia, Sociologia, ou seu corpo teórico já "nasceu” psicológico? Quanto à acusação de a Psicopedagogia possuir "interesses escusos" no que se refere a uma reserva de mercado, perguntamos: qual parece ser a preocupação do CFP ao tentar impedir a regulamentação desse outro conhecimento? Não há, também, além de uma inegável preocupação ética do CFP com a propagação e utilização de conhecimentos psicológicos por profissionais não habilitados, uma tentativa de proteger o psicólogo escolar da concorrência do psicopedagogo e, mais ainda, o psicólogo clínico que recebe em seus consultórios o aluno com problemas na escola?

Outro aspecto apontado é o uso de técnicas privativas do psicólogo pela Psicopedagogia. Nesse aspecto, os psicopedagogos argumentam que usam técnicas que não são de uso exclusivo da Psicologia, pois são, principalmente, testes de inteligência e projetivos. A questão torna-se realmente complexa nesse momento em que não há estudos que descrevam a prática do psicopedagogo. Nesse caso, um problema legal estaria colocado, mas que, por si só, não seria justificativa suficiente para o impedimento do regulamentação de uma profissão, dado que a Psicopedagogia pode, muito provavelmente, construir seus próprios instrumentos de trabalho.

A "Síndrome de Caim" parece concretizar-se quando percebemos a existência de um impasse, de acusações expostas por uma categoria que, por mais desagradável que lhe pareça, assemelha-se por parentesco de idéias e posturas, ao "irmão Abel", alvo de ataques e retaliações.

A crítica feita aos argumentos do CFP não pretende isentar o grupo de psicopedagogos candidatos a profissionais, de possíveis 
cobranças quanto aos aspectos apontados. Concordamos com o CFP no que diz respeito ao tempo de duração dos seus cursos de especialização no Brasil. O fato de serem, em sua maioria, de apenas dois anos, aceitando qualquer graduação de seus alunos, sem que haja uma equivalência no que diz respeito a disciplinas lecionadas e cargahorária, será que não torna essa Psicopedagogia tão variada e sem identidade a ponto de comprometer a atuação desse profissional? Poderíamos, a partir dos cursos de Psicopedagogia no Brasil, falar de uma única profissão psicopedagógica? Concordamos com a possibilidade de a Psicopedagogia constituir-se a partir de uma visão equivocada do problema de ensino-aprendizagem, tão criticada pelos estudos descritos. Concordamos que ela se aproveita da existência de uma demanda pela "cura" desses problemas e apresenta-se como especialista neles. Concordamos que a Psicopedagogia não pode apropriar-se de técnicas psicológicas na sua formação e atuação, sob o risco de agir ilegalmente.

No entanto, queremos apontar que o CFP utiliza-se de argumentos que poderiam, muitos deles, facilmente ser apontados contra a própria Psicologia, caso estivéssemos sempre a par do seu processo de construção de uma identidade de formação e atuação no Brasil. Somos levados a pensar que há, com certeza, lacunas na teoria, na formação e na prática do psicopedagogo que poderiam ser questionadas. Mas nós, psicólogos, precisamos, através de nosso Conselho, ter argumentos mais respaldados em critérios outros, que nos apontassem as dificuldades para a existência do profissional de psicopedagogia sem que, com isso, esquecêssemos ou não considerássemos a própria história da Psicologia no Brasil.

\section{Referências}

Andaló, C. S. A. (1984). O papel do psicólogo escolar. Psicologia: Ciência e Profissão, 4(1), 43-46.

Bastos, A. V. B. (1988). Áreas de atuação: em questão o nosso modelo profissional. In Conselho Federal de Psicologia (Org.), Quem é o psicólogo brasileiro? (pp.163-193). São Paulo: EDICON.

Bossa, N. (1994). A Psicopedagogia no Brasil: contribuições a partir da prática. Porto Alegre: Artes Médicas. 
Conselho Federal de Psicologia (1999). A criação da profissão de Psicopedagogia é um equívoco! [On-line]. Federal Net - Conselho Federal de Psicologia. <http://psicologia-online.org.br/federalnet.html>.

Jucá, M. R. B. L. (1999). Síndrome de Caim: Psicologia Escolar, Psicopedagogia e o "fracasso escolar" como mercado de trabalho. Monografia de especialização não-publicada, Universidade Federal do Rio Grande do Norte, Natal.

Maluf, M. R. (1994). Formação e atuação do psicólogo na educação: dinâmica de transformação. In Conselho Federal de Psicologia (Org.), Psicólogo brasileiro: práticas emergentes e desafios para a formação (pp.156195). São Paulo: Casa do Psicólogo.

Mello, S. L. (1975). Psicologia e profissão em São Paulo. São Paulo: Ática.

Reger, R. (1981). Psicólogo brasileiro: educador ou clínico? In M. H. S. Patto (Org.), Introdução à Psicologia Escolar (pp. 9-16). São Paulo: T. A. Queiroz.

Ribeiro, P. R. M., \& Guzzo, R. S. L. (s.d.). Afinal, o que pode fazer o psicólogo escolar? Manuscrito não-publicado.

Sindicato dos Psicólogos no Estado de São Paulo/Conselho Regional de Psicologia - $6^{\text {a }}$. Região (1984). O perfil do psicólogo no Estado de São Paulo. São Paulo. Cortez.

Yamamoto, O. H., Souza, I. M. S., Oliveira, I. A., Silva, L.N. M., Freire, M. A. A., Rocha, R. M., \& Alves Filho, S. (1990). A Psicologia Escolar em Natal: características e perspectivas. Psicologia: Ciência e Profissão, 2/3/ 4, 40-49.

Yamamoto, O. H., Spinelli, S. M. A., \& Carvalho, D. B. (1996). O psicólogo escolar em Natal: em busca de uma identidade profissional. Psicologia: Reflexão e Crítica, 9(2), 269-291.

Margareth R. B. Lima Jucá é mestranda do Programa de PósGraduação em Psicologia da Universidade Federal do Rio Grande do Norte sob orientação do prof. Dr. Oswaldo H. Yamamoto, bolsista da CAPES e psicóloga. Endereço para correspondência: Av. Amintas Barros, 4039, apto. 201, Lagoa Nova, 59075-250, Natal, RN.

E-mail: margarethjuca@ig.com.br.

Sobre a autora 